\title{
Interprofessional Teamwork: The role of Professional Identity and Signature Pedagogy - A mixed methods study
}

\section{$\underline{\text { Abstract }}$ \\ Purpose}

One overlooked determinant of interprofessional teamworking is the mobilisation of professional identity. Taking a health or social care practitioner out of their professional silo and placing them in an interprofessional team setting will challenge their professional identity. Using the theory of signature pedagogy we investigate the challenges and what is needed to support practitioners to mobilise their professional identity to maximise teamwork.

\section{Design/methodology/approach}

A cross sectional mixed methods study was undertaken in the form of three focus groups, with members of health and social care teams in Wales, UK. Using nominal group technique, participants explored and ranked the challenges and benefits of mobilising their professional identity within an interprofessional setting.

\section{Findings}

We found the findings on mobilising professional identity to be aligned closely with the three signature pedagogy apprenticeships of learning to think and to perform like others in their profession and to act with moral integrity. The biggest challenge facing practitioners was thinking like others in their profession while in an interprofessional team.

\section{Research limitations/implications}

The focus of this study is health and social care teams within Wales, UK, which may limit the results to teams that have a similar representation of professionals.

\section{Practical implications}

Health care leaders should be aware of the opportunities to promote mobilisation of professional identity to maximise team working. For example, at induction, by introducing the different roles, and shared responsibilities. Such practical implications do have implications for policy as regards interprofessional team development and organisational commitments to adult learning and evaluation.

\section{Originality/value}

We believe this is the first study of professional identity of interprofessional healthcare and social professionals using signature pedagogy to gain a better understanding of team working.

Keywords: professional identity, mobilisation, teams, health and social care, signature pedagogy

Article type: Research paper

\section{Introduction}


Worldwide the significance of teamwork in the delivery of care is well established; patient experience is improved (Lown and Manning, 2010), patient satisfaction increased (Meterko et al., 2004) and the care delivered is safer (Institute of Medicine, 2000; Richter et al, 2016). Equally many of the essential factors to support teamworking are well known such as sharing a common vision, effective communication with team members working interdependently and supportive relationships (Nancarrow et al 2013). Despite this wealth of knowledge, one often overlooked determinant of interprofessional teamworking is the mobilisation of professional identity (Best and Williams, 2018a). Professional identity is the way a person identifies themselves by the work they undertake and is influenced by experiences in the workplace (Caza and Creary, 2016), both from work that is undertaken and a perception of 'uniqueness' (Van Maanen and Barley, 1984). The mobilisation of professional identity means the processes whereby a practitioner actively engages and manages that identity while working in an interprofessional team and while carrying out their continuing professional development (Best and Williams, 2018a). Nevertheless, there is a preference for practitioners to work with their colleagues from the same profession (Ferlie et al., 2005) as usually there is a shared understanding of the profession, scope of practice, forms of communication which are often reinforced by membership of the professional body.

A recent scoping review examining professional identity in interprofessional teams (Best and Williams, 2019) identified the importance of socialisation for the creation of a professional's identity and the role of others (Falk et al., 2017). By taking a health or social care practitioner out of their professional silo and placing them in an interprofessional team setting their professional identity will be challenged. Threats to professional identity increase professional solidarity and salience (Badea et al., 2010), along with fostering defence of interprofessional distinctions (Hornsey and Hogg, 2000; Norris, 2001). There needs to be a willingness to mobilise one's personal and professional identity to ensure effective interprofessional practice (Beech and Verity, 2019). Often challenges present when providing care across the organisational boundaries of social care and health care which have different implicit and explicit ways of working. Working across boundaries removes the security of the confirmation bias provided by working alongside homogenous practitioners and opens team members up to differing views and perspectives on the way to deliver care. As health and social care increasingly combine forces to deliver care it is essential that we explore how health and social care professionals in teams function in this setting.

To successfully work within an interprofessional team requires health and social care professionals to be able to think beyond their own professional boundaries, demanding flexibility or mobility of their professional identity in order to offer the adaptability required to deliver care (Best and Williams, 2018b; Beech and Verity, 2019). Within the professional identity literature the focus is 
placed on the dominant health professions (such as medicine and nursing e.g. Fitzgerald and Teal, 2004; Lotan 2019) and in particular on student development of professional identity (e.g. Browne et al 2018, Joynes, 2018, Stull and Blue, 2016 amongst others). This oversight neglects the challenges faced by the wider health and social care team (for example, social workers, physiotherapists and pharmacists) who are also participants in interprofessional teams. Without consideration of other professional groups, each individual profession will have their own established identity alongside different approaches to care provision, different priorities and different documentation or terminology (McNeil et al.,2012). The challenge for managers and organisations is how to support these different profession groups to develop a shared understanding of how professional identity can best be managed within an interprofessional team setting. Schulman (2005) theorised that the method for education of professionals, or what is termed signature pedagogy, including those outside health and social care, demands a trifold approach of 'apprenticeships'; i) a cognitive apprenticeship to learn to think like others in your profession, ii) a practical apprenticeship to learn how to perform like those in your profession, and, iii) a moral apprenticeship to learn how to act with moral integrity (Shulman, 2005). Hence signature pedagogies are approaches to teaching that are idiosyncratic to each professional group and are found throughout the training of each profession (Gurung, Chick \& Haynie, 2009) and "nearly always entail public student performance" (Shulman, 2005, p. 57) making the conformity to or fitting in with the profession apparent to peers and senior professionals. With their unique professional identities and signature pedagogies there are clearly implications for teamworking and interprofessional education with individual team members responding according to their own professions' predisposition.

Unsurprisingly, therefore the concept of signature pedagogy with its three types of apprenticeships is commonly found in education including in health care management studies (Sambrook, 2009), public administration (Abel, 2009), psychology (Goodyear, 2007), social work (Larrison and Korr, 2013), doctoral education (Olson \& Clark, 2009), and the humanities (Benmayor, 2008). In particular, signature pedagogy has been applied in undergraduate placement learning in social work (Asakura et al., 2018) and in higher education (Nørgård et al., 2017). However, if teaching and learning about professional identity through signature pedagogies is only considered in the siloed setting of formal undergraduate, postgraduate, or continuing professional education then that teaching and learning misses the ways that professional identity can be developed iteratively in an informal or unplanned manner in the workplace. In this paper we are examining how signature pedagogy can be applied outside recognised education settings to the everyday learning experiences of health and social care practitioners, particularly when working as a member of an interprofessional team. 
Similarly, Lucas (2015) examined the pedagogies, typically associated with the teaching of quality improvement in health and social care, that have traditionally relied on a narrow focus of content transmission, didactic sessions that are spatially and temporally distant from clinical work and quality and safety projects segregated from the provision of actual patient care (Cooke et al.,2011). Referring to Shulman's (2005) explanation that signature pedagogies form habits of the mind, habits of the heart and habits of the hand and so influence professionals' cultures and their professional attributes., Lucas (2015) proposed identifying the desirable habits (in this case for improvers who need to work with all professions) and then developing the best pedagogies that will lead to the desirable habits which could include coaching, peer teaching, and enquiry-led approaches such as action research. The development of these habits is not seen as an alternative to knowledge or skill, but complementary (Lucas, 2015). In order to develop strategies to support the mobilisation of professional identity we need to understand the pedagogies associated with the actions of those working in a context where such activity is undertaken. We propose that an interprofessional team which encompasses various professions across health and social care provides this context.

\section{Signature Pedagogy - theoretical framework}

The term signature pedagogy was first coined by the Carnegie Foundation for the Advancement of Teaching with research that aimed to explore pedagogies and practices within professional education. As previously noted, the concept has since been widely applied to teaching and learning in many academic domains. Shulman (2005, p22) defines pedagogies as "pervasive, routine and habitual" and are identifiable as the educational method which is specific and distinctive to a discipline, for example the case method approach of law education, which emphasizes skills in "thinking like a lawyer," and the well-known performance-in-action approach of clinical rounds within medical school training (Shulman, 2005).

Here we draw on Shulman's identification of the triad of thinking, performing and acting with integrity to inform our view of a signature framework for supporting practitioners to mobilise their professional identity when working in interprofessional teams. Such working will require individuals to often work close to the boundary of their profession or perhaps in some instances outside the boundary, though not outside their scope of practice. Shulman's (2005) framework is used here to assess three components of signature pedagogy.

Shulman (2005) noted that professional pedagogies help to shape the emerging practitioner's future actions and behaviours, as well as facilitate understanding about values and constructs within the individual discipline. We are interested to explore which pedagogies help to shape the professional identity of practitioners who are either no longer working with or not only working with colleagues 
from their own discipline or profession and to identify what would be helpful for practitioners to support this interdisciplinary working.

Aim: Using the theory of signature pedagogy the aim of this paper is to investigate the perceptions of practitioners' professional identity as they work within interprofessional health and social care teams. Specifically, the research questions are,

1. What are the benefits and challenges of professional identity when working in an interprofessional team?

2. How do these align with signature pedagogy i.e.

2.1. What it means to think like others in your profession when in an interprofessional team

2.2. What it means to perform (e.g. act and serve the patient/client) like others in your profession when in an interprofessional team

2.3. What it means to act with integrity (moral, ethical, personal and social responsibility regarding the performance of one's practice actions). This component interlinks with thinking and performing and involves the development of professional and practical judgement.

3. What does this mean for supporting practitioners in the mobilisation of their professional identity?

\section{Methods}

\section{Context}

Participants for this study were based in south Wales in the UK and were health or social care professionals employed by the University Health Board or Local Authority. Delivery of care in Wales is underpinned by the concept of Prudent Healthcare (Welsh Government, 2016) which has four principal pillars. The first emphasises the need for equal partnerships between the public and professionals which may be achieved through co-production. The second pillar refers to caring for those patients with the greatest health need first. The third pillar reminds practitioners of prudency and safety by stating only to do what is needed and to do no harm. The final pillar refers to reducing inappropriate and unnecessary variation through the delivery of evidence-based approaches. Through Prudent Healthcare, therefore, the expectation of interprofessional service delivery is high (Welsh Government, 2016) especially via the concept of "only-do-what-only-you-can-do" where practitioners are expected to assess a patient/client's needs and distribute care delivery across the interdisciplinary team.

\section{Research design and ethics}


A cross sectional mixed methods study was undertaken in the form of three focus groups. Ethical approval was provided by the College of Human \& Health Sciences Research Committee (CHHS-2311-2017-SJW), Swansea University and organisational approval was gained from each of the participating health boards before approaching participants. Focus group participants provided written consent before the focus group, after reviewing the participant information and having the opportunity to ask questions.

The nature of this interdisciplinary study means participants will have experienced different training, professional development and subsequent roles and responsibilities. It is these different views held within the teams that we wanted to explore and to then develop a consensus in relation to professional identity, how it is managed and developed within interdisciplinary teams. This can be challenging and has potential for hierarchical relationships which can lead to misrepresentation of views and potential bias (Allen et al., 2004). Focus groups provide the opportunity for group discussion and to gather rich information on a selected topic, but this discussion alone is unlikely to provide consensus (Kreuger and Casey, 2000) and additional approach was sought. Two techniques specifically used to develop consensus are the Delphi method, with multiple rounds of questionnaires, and the Nominal Group Technique, a structured method used in group settings (Carrasco et al., 2015; Fink et al., 1984). It is the latter technique that was selected due to the faceto-face interaction of the focus groups.

\section{Participants and recruitment}

The Quality Improvement leads from the five University Health Boards in South Wales were recruited to share an email project flyer with their local health and social care interprofessional teams. Team leads were invited to contact the researchers directly if they were interested in participating. Current health and social care practitioners working within an interprofessional team met the inclusion criteria. We were looking for either individuals or whole teams fulfilling the inclusion criteria to participate and ultimately the study attracted three whole teams, based in the community, which totalled 31 participants from three University Health Boards and three Local Authorities (table I). Participants, who represented various professions, were mainly female and the majority were co-located with their interprofessional team members. Years since qualification ranged from newly qualified to over 20 years, with the majority of members joining the team within the last three years.

Three focus groups (group 1, $n=6$; group 2, $n=11$; group 3, $n=14$ participants) were arranged with each of the teams that responded to the request to participate. The size and composition of the focus group is governed by the purpose of the investigation (Cantrill et al., 1996). For this study the 
aim was to explore and capture the views of different professions within an interprofessional team. Therefore, limits were not imposed on the participant numbers to try and ensure all professionals within each team were represented. The focus groups were held at the premises where the majority of the team members were based. The duration of the focus groups was between 2 and 2.5 hours. Times varied due to the numbers within the teams.

Table I. Characteristics of focus group participants

////Insert table I about here////

\section{Data collection tools and approach/procedures}

Each focus group was facilitated by two members of the research team. Participant information sheets were emailed to team leads before the focus groups were held, and hard copies were also available for those that had not seen or had the opportunity to read them beforehand. We purposively designed the focus group questions to be open to encourage debate and we were interested in gathering participants' views on their perceptions of their professional identity from the viewpoint of their own specialist profession. The key objectives of the focus groups were:

(a) To identify the most important benefits of professional identity in interprofessional team working to participants.

(b) To identify the most important challenges of professional identity in interprofessional team working to participants.

(c) To assess what this mean for supporting practitioners in the mobilisation of their professional identity

After an icebreaker, followed by a general discussion about professional identity while working in a team, participants were asked to identify the benefits and challenges of professional identity in an interprofessional teamworking environment. The nominal group technique (NGT) was used (table II) to structure the responses to these questions, where each member of the group was first asked to provide their reflections on what the benefits were to them to working as a member of the team. Using a 'round-robin-format' each team member was asked in turn until all answers were shared. These were reviewed by the team and grouped if there were similar answers. Each team member then had up to ten votes to distribute across the identified benefits - these could be placed all on one benefit or distributed across up to ten benefits. Once the voting had taken place the benefits 
were arranged according to the greatest number of votes. The same exercise was undertaken with the team to identify the challenges. After each exercise teams were asked to review the scores and comment on the ratings - as to whether there were any surprises. These data were recorded by the research team. The NGT enabled all team members to participate and to establish a ranking of the most and less important concepts. Examples of the output from the NGT activity are shown in supplementary file 1 . The participants were also asked to identify what support might help for them to mobilise their professional identity; suggestions were captured by the research team.

Table II: Nominal Group Technique phases. Adapted from Cantrill et al., (1996)

////Insert table II about here/////

\section{Data analysis}

Data from the NGT activities were coded in two ways. First, we analysed all the items reported during the NGT work using inductive thematic analysis (Braun and Clarke, 2006). Secondly, we coded the results from the NGT work from the three focus groups (FG) using the signature pedagogy 'apprenticeships' using deductive thematic analysis (table III). For both analyses items were coded independently by two researchers (SB and SW) and differences were discussed regularly to form an agreement. Data relating to the support required for the mobilisation of the professional identity, captured by the facilitators, were analysed using content analysis. These were checked for accuracy by the researchers that facilitated the focus groups.

Table III: Apprenticeships coding guide

////Insert table III about here/////

\section{Findings}

The NGT was used to help form a consensus from each of the teams. As well as the benefits and challenges, participants were also encouraged to identify the highest priorities for actions regarding professional identity when preparing professionals for team working and for them to consider who should take those actions. First, we present the common themes identified from the analysis of the items participants identified during the NGT (see table IV and, for more detail, see the 
supplementary information), then secondly we share the key findings by signature pedagogy coding. In total there were 246 votes for benefits of professional identity in interprofessional teams and 249 votes for the challenges. Finally, we report on the support required for the mobilisation of professional identity

\section{Common themes identified from the Nominal Group Technique activities}

\section{Benefits of Professional Identity for members of interprofessional teams}

Benefits of a specialist professional identity while working in an interprofessional team presented within three themes (see table IV), i) team functioning e.g., having a clear team structure, accountability and delegation; ii) working as a collective e.g., sharing responsibility and better understanding each other's roles; and, iii) delivering patient centred care e.g., the team set up around the patient and having a holistic approach.

\section{i. $\quad$ Team functioning}

Specialist professional identity was viewed as a key benefit when participants described the structure and functioning of their teams. Professional identity helped to provide clarity around membership (i.e. which professions to include), how teams were structured and identifying lines of accountability and areas of delegation. These organisational features were perceived as particularly helpful for managers of the interprofessional teams who supervised team members outside of their own profession, for example, a social worker managing healthcare professionals and vice versa.

\section{ii. Working as a collective}

The second key benefit focused on the collective working of the teams. Having a unique professional identity helped team members to appreciate and understand each other's profession and their role within the team and how individual roles interacted or intersected with other professions within the team. This level of understanding fostered an environment supportive of shared responsibility for the patient/client group.

\section{iii. Delivering patient-centred care}

Another key benefit that was evident from the NGT scores and group discussions was the ability to provide the best possible care and support required by their patients/clients. Professional identities enabled team members to identify when to pull in the skills of their team members as and when required by patients/clients. A clearer understanding of each other's unique professional identity enabled them to provide holistic care which was often facilitated by joint visits - for example 
dietician and occupational therapists visiting the patient/client. Clarity around specific professional identity among team members supports the design and delivery of patient-centred care.

\section{Challenges of Professional Identity for members of interprofessional teams}

Challenges focused on the understanding of i) how the team works e.g., different ways of working are not understood within the team; ii) influences from outside the team e.g., different budgets and IT systems; and iii) knowing your boundaries e.g. working outside your comfort zone and role ambiguity.

\section{i. How the team works}

Professional identities unique to a profession can provide challenges in relation to how interprofessional teams operate. For example, professions have different systems and requirements for recording patient information along with different ways of working associated with operational processes and lines of accountability. Participants discussed finding the time and opportunities to understand these differences can be challenging particularly for new members joining the team.

\section{ii. Influences from outside the team}

Managing the influences from outside of the interprofessional team was challenging for many of the participants. There were deficits in the infrastructures to support the various professions working within an interprofessional team. The lack of integrated IT systems was a key example and therefore required professions to work on different systems and find ways to ensure key information was shared to support their interprofessional practice. This was most likely to occur between social workers and healthcare professionals. These two professional groups were funded usually from different budgets which again affected the level of integration that could be achieved across the various professions and the team. However, healthcare professionals reported similar IT and structural issues between acute and community settings.

\section{iii. Knowing your boundaries}

Understanding each specialists' professional identity within an interprofessional team setting and how this is mobilised by team members can clearly have benefits as noted above, particularly if there is a clear understanding of each other's roles. However, participants also spoke about the challenges associated with the knowing and managing the boundaries of their professions, which many participants suggested can be blurred when working in interprofessional teams. It was evident from the focus group discussions that individuals and the wider team needed to be clear about what the professional boundaries were of each of its team members and how these conversations were 
best managed. Many felt to develop a shared understanding of these boundaries was a challenge given the continual need to provide care for their patients/clients. It was suggested that clarity of these professional boundaries developed over time and required stability among team membership.

\section{////Insert table IV about here//////}

Table IV. Data from Nominal Group Technique Activity

\section{Key findings by signature pedagogy coding}

The key findings by signature pedagogy coding of apprenticeships can be seen in in figure 1 . Collectively the results demonstrate that working in an interprofessional team was reported as a benefit to 'acting with integrity' however the cognitive challenge was more demanding when endeavouring to 'think' like others. The practical apprenticeship was equally challenging and of benefit.

Figure 1: Cumulative ranking of findings by signature pedagogy apprenticeship.

////Insert figure 1 about here//////

When the data are analysed by the highest and lowest scoring benefits the highest ranked benefit of professional identity in an interprofessional team was the practical apprenticeship of learning how to perform like those in your profession. This may be considered surprising as learning to perform while surrounded by other professional groups may be thought of as challenging though this may reflect the years of experience accumulated by members of the team.

The highest ranked challenge to professional identity in an interprofessional team was clearly the cognitive apprenticeship of learning to think like others in your profession, reflecting the high level findings in figure 2. Interestingly, the second highest ranked challenge is learning how to perform like those in your profession which was previously identified as the key benefit suggesting performing like those around you is prominent in the minds of these practitioners. 
Figure 1: Coding by signature pedagogy: Highest and lowest ranked benefits and challenges of professional Identity in an interprofessional Teams

$/ / / /$ Insert figure 2 about here/////

If we examine the results of the individual focus groups we can see some interesting patterns (table IV). For example, focus group 1 the codes 'perform' and 'act' were prevalent themes within the benefits with sharing of responsibility, problems and exploring options being important to the team members. For the challenges, these we linked more with 'thinking like others' and issues around working with others, working outside one's comfort zone and the inability to say no to another team member when perhaps asked to attend a joint visit were viewed as challenges.

In terms of focus group 2 the two highly ranked benefits were associated with 'performing' in a interprofessional team which included being supported within their roles, delivering patient centred care, education being delivered from various perspectives and working within their scope of practice. The membership of this team was interesting in that it included practitioners as well as clinical researchers, and several members were relatively new to joining the team. In terms of the challenges for this group, these were mostly linked to 'thinking like others' in an interprofessional team and were mainly associated with different ways of working and how the interprofessional working impacts on patients.

The benefits relating to 'acting with integrity' featured more among members of focus group 3 . The importance of promoting shared values and ensuring the team focused on the patient/user were key to this team. In terms of challenges, this group found the performing as an interprofessional team somewhat testing. Many of these difficulties were associated with structural issues such as budgetary and IT constraints and the limited integration of services. This team included members employed by both the University Health Board and the Local Authority and hence the challenges mentioned around working for different employers and managing policy.

\section{Support required for the mobilisation of professional identity}

It was evident from the analysis of the focus group discussions relating to the support required to facilitate the mobilisation of their professional identity, while working in an interprofessional team, that there were three key areas that could be considered:

a. Interprofessional training and continuous professional development opportunities. For the majority of participants training and education was by individual professions and often associated with the professional bodies. 
b. Regular sessions for the team to actively reflect together on the contribution of each profession and to review how they were working as an interprofessional team.

c. Induction to include sessions on managing and mobilising of each specialists' professional identity and time to understand the role of other professions within the team.

\section{Discussion}

It was evident from the comments and feedback from the focus groups that teams were keen to develop a better understanding of the unique professional identities of those in the team. Identifying the key benefits and challenges associated with professional identity in interprofessional teams created considerable discussion among team members. The NGT enabled all members to contribute and provided equity across the hierarchy within the teams which was important because participants represented managers, professionals, assistants and placement students. As the NGT process encouraged participation across all participants it enabled us to collate the views from all professions represented.

It was clear from the focus group discussion that the majority of participants had not previously considered the role of their professional identity and how this is managed and mobilised within their interprofessional teams. It would seem that prior to the NGT groups, participants were unfamiliar with the concept of professional identity and/or lacked the opportunity to reflect on their individual professional contribution within the interprofessional team context.

The inductive thematic analysis identified the benefits as being related to how the team is structured and functions, with an emphasis on working collaboratively and the importance of delivering patient-centred care. The analysis found the challenges as, again, being tied to team working but now the issues were around the organisational systems supporting the interprofessional working. External influences and managing professional boundaries were reported as being challenging, implying the need for active leadership and management (Workman and Pickard, 2010). These results are complementary to the deductive thematic analysis on the signature pedagogy 'apprenticeships'.

The implications of mobilising specialists' professional identities for managers are significant as experiences in the workplace play a key role in defining professional identity (Caza and Creary, 2016). For example, managers need to ensure teams are supported to reflect on their individual roles and contributions (Kreindler et al., 2012) and to create the space to facilitate sessions where members can explore each other's role and where synergies and overlaps occur. The potential activities available for teams and individuals to influence how professionals think, perform and act with integrity are varied and we discuss each of these signature pedagogy apprenticeships in turn 
Thinking as a member of an interprofessional team: From the high-level results and the ranked challenges and benefits it is clear that thinking as a member of an interprofessional team was more likely to be seen as a challenge. During the focus groups several participants spoke about the need to regularly review how they work as an interprofessional team so they have a better understanding of each other's roles (Falk et al., 2017). Different ways of working across the different professions was not always understood. Therefore, creating this time and space is crucial to the working of the team as it is an individual's unique professional identity that determines his/her work attitudes and behaviours (Hogg, M. A. and Abrams, 1988; Siebert and Siebert, 2005). Deciding how services are delivered is ultimately dependent on practitioners' behaviour that in turn establishes the quality of care received by patients/clients.

Performing as a member of an interprofessional team: Performing was equally as much a challenge as a benefit. Opportunities to practice team members' performances, demonstrating that they belong to the wider team, and not just their own profession, are present throughout clinical/social care working practice. Shared home visits with joint assessments provide a vehicle for professionals to display their common practice while also sharing their profession specific skills. In service training has been previously identified as useful events for focusing on professional identity though it is important for professionals to access both multi and uniprofessional training (Best and Williams, 2018b).

Acting with integrity: Overall working in an interprofessional team was reported as a benefit. In order to promote the concept of acting with integrity it is essential to create opportunities for teams to openly discuss expected contributions from individual professions. Also, the teams need to discuss shared team responsibilities to enhance their working. Open mindedness and the willingness to question one's own position are fundamental to enabling the discussion across professions (Beech and Verity, 2019; Sinkula et al, 1997). The influence of the professional and regulatory bodies will be central for professionals learning to act with integrity because these bodies establish what is deemed acceptable in professional practice. Setting an expectation or acceptability of working and sharing roles and accountability with other professions will facilitate individuals to act with integrity (Iserson, 2019).

Limitations: Our research is limited to three focus groups, however, the teams attending represented a broad cross section of professionals from health and social care. Although the teams represented three health boards and three local authorities in Wales, we recognise this is not representative of the international interest in the topic. It is therefore imperative that further research builds on this study and takes the pedagogical insights provided here to support those in 
roles where managing and mobilising their professional identity is key. The health and social care practitioners who attended the sessions were all based in primary care and it would be interesting to repeat it in the acute care setting.

\section{Conclusion}

With the growing universal prominence of integrated health and social care systems comes the need for interprofessional team working, which requires professionals to think beyond their own professional boundaries and mobilise their own unique professional identity (Best and Williams, 2018b). Using the theory of signature pedagogy, this paper has examined the perceptions of practitioners' professional identity as they work in interprofessional health and social care teams to address three questions.

Firstly, our results have shown it is important to establish from the team members what they perceive as the benefits and challenges of professional identity when joining or working in an interprofessional team so that education interventions can be tailored to the needs of the group. As we have seen here, these are likely to vary depending on the structure, professions represented in the team and the maturity of the team membership. There is value in exploring professional identity when the team is formed, as the team matures, and when new members join the team. Team meetings and education events are examples of occasions when professional identity can be explored.

Secondly, using the theoretical lens of signature pedagogy, we have found the findings to be aligned closely with the three signature pedagogy apprenticeships of learning to think and perform like others in their own profession and to act with moral integrity. Thinking like others in their own profession presented the greatest challenge while acting with moral integrity was more straightforward. Supporting health and social care practitioners to retain their professional identity, while also embracing the fluidity of interprofessional working, needs to be a priority for health and social care managers to optimise each professional contribution to patient care. The opportunity for teams to come together to discuss and explore the various facets of professional identity was well received by the participants. We focused on the psychology and construct of professional identity rather than the unique knowledge attributed to each profession. This unique knowledge both profession and context specific, will contribute to professional identity and it could benefit from further study to untangle the overlapping relationship with the three apprenticeships. Additionally, those with management responsibilities indicated they were intending to provide other opportunities to enable discussions to continue. We endorse such activity and suggest further 
research is required to assess the methods (e.g. induction, team meetings, audits, significant event analysis) used to support such discussions to happen within the workplace.

Thirdly, we have started to explore what this research means for supporting managers and practitioners in the mobilisation of their professional identity. We can see that similar to quality improvement, mobilising professional identity is something that largely occurs within the workplace. Given the growing agenda of integrating health and social care we propose that signature pedagogies which encourage habit forming are important to how interprofessional teams work. Therefore, it is imperative that we tease out the best pedagogies that will support this development. Such activity needs to be work-based (e.g. coaching), interprofessional (e.g. peer teaching) and not segregated from the provision of patient/client care.

\section{Implications for research:}

There is extant body of literature on the development of professional identity within the context of students and education (Mossop et al., 2013). Here we have examined professional identity within a workplace setting of health and social care professionals working as members of interprofessional teams. We have identified the implications of this research for those charged with the management and professional development of these team members to ensure activities are supportive of creating opportunities for dialogue learning and habit forming. There are additional implications for future research. We have observed that the cognitive apprenticeship of learning to think like others in your profession provided the greatest challenge for health and social care practitioners' professional identity. Further investigation into influences on this cognitive apprenticeship would be of interest. We also theorised that shifting health and social care professionals out of their professional identity silo would have an influence on their behaviour and therefore on the care patients receive.-

Further research needs to investigate how an individual's professional identity can contribute to a team's shared professional identity and in turn benefit patients' care. For example, can teams use a particular professional pedagogy to facilitate more effective team functioning? We have identified intervention strategies to promote a team's shared professional identity, for example, dialogue learning at induction or team meetings, or habit forming through significant event analyses, and these strategies need evaluating.

\section{Implications for practice and policy:}

We have noted the important role managers play in supporting practitioners to retain their professional identity, whilst working within an interprofessional team. Regular opportunities need to be provided where team members can meet to explore how professional identity is mobilised and 
managed within the team, this is particularly important for new members joining the team. Induction programmes and professional development programmes for interprofessional teams would also benefit from sessions relating to professional identity. Having recognised the commitment required by organisations, there is also a role for professional bodies and policy to play as regards interprofessional team development and organisational commitments to adult learning and evaluation.

\section{List of tables, figures and supplementary information}

Table I. Characteristics of focus group participants

Table II: Nominal Group Technique phases. Adapted from Cantrill et al., (1996)

Table III: Apprenticeships coding guide

Table IV. Data from Nominal Group Technique activity

Figure 1: Cumulative ranking of findings by signature pedagogy apprenticeship.

Figure 2: Coding by signature pedagogy: Highest and lowest ranked benefits and challenges of professional Identity in an interprofessional Teams

Supplementary information 1: Examples of the output from the NGT activity 1 and 2

Supplementary information 2: Detail of signature pedagogy coding

\section{References}

Abel, C. F. (2009). "Toward a signature pedagogy for public administration". Journal of Public Affairs Education, Vol. 15, pp. 145-160. 
Allen, J. Dyas, J. and Jones, M. (2004), "Building consensus in health care: A guide to using the nominal group technique", British Journal of Community Nursing, Vol. 9 No. 3, pp. 110-114.

Asakura, K., Todd, S., Eagle, B., Morris, B., (2018). "Strengthening the Signature Pedagogy of Social Work: Conceptualizing Field Coordination as a Negotiated Social Work Pedagogy". Journal of Teaching in Social Work. Work 38, 151-165. https://doi.org/10.1080/08841233.2018.1436635.

Badea, C. Jetten, J. Czukor, G. and Askevis-Leherpeux, F. (2010). "The bases of identification: When optimal distinctiveness needs face social identity threat", British Journal of Social Psychology, Vol. 49 No. 1, pp. 21-41.

Beech, C. and Verity, F. (2019), "Health and social work practitioners' experiences of working with risk and older people: The interconnectedness of personalities, process and policy, Journal of Integrated Care, Vol. 28, No. 2, https://doi.org/ 10.1108/JICA-08-2019-0036

Benmayor, R. (2008). "Digital storytelling as a signature pedagogy for the new humanities". Arts and Humanities in Higher Education, Vol. 7, pp. 188-204.

Best, S., and Williams, S. (2018a). "Professional identity in integrated health and social care teams: a scoping review of the literature". Journal of interprofessional care, Vol. 33 No. 2, pp. 170-181.

Best, S., and Williams, S. (2018b). "Integrated care: mobilising professional identity". Journal of health organization and management, Vol. 32 No. 5, pp. 726-740.

Best, S. and Williams, S. (2019) 'Professional identity in interprofessional teams: findings from a scoping review', Journal of Interprofessional Care. Taylor \& Francis, 33(2), pp. 170-181. doi: 10.1080/13561820.2018.1536040.

Braun, V., Clarke, V., (2006). "Using thematic analysis in psychology". Qualitative Research in Psychology. Vol. 3, pp. 77-101.

Browne, C., Wall, P., Batt, S., Bennett, R., (2018). "Understanding perceptions of nursing professional identity in students entering an Australian undergraduate nursing degree". Nurse Education in Practice. Vol. 32, pp. 90-96. https://doi.org/10.1016/j.nepr.2018.07.006

Cantril, J. Sibbald, B. and Buetow, S. (1996). "The Delphi and Nominal Group Technique in health services research", The International Journal of Pharmacy Practice, June, pp. 67-74.

Carrasco, J.M. Lynch, T.J.;Garralda, E. Woitha, K Elsner, F. Filbet, M. Ellershaw, J.E. Clark, D. and Centeno, C. (2015). "Palliative care medical education in European universities: a descriptive study and numerical scoring system proposal for assessing educational development", Journal of Pain \& Symptom Management. Vol. 50 No. 4, pp.516-23.e2. DOI:

https://doi.org/10.1016/i.jpainsymman.2015.04.019

Caza, B., and Creary, S.J., (2016). "The construction of professional identity", in: Wilkinson, A., Hislop, D., Coupland, C. (Eds.), Perspectives on Contemporary Professional Work: Challenges and Experiences. Edward Elgar Publishing, Cheltenham, UK. pp. 259-285.

Cooke, M, Ironside, PM, and Ogrinc GS. (2011). "Mainstreaming quality and safety: a reformulation of quality and safety education for health professions students". BMJ Quality \& Safety, Vol. 20 No. Suppl 1, pp. i79-82. 
Falk, L. et al. (2017) 'Nursing assistants matters-An ethnographic study of knowledge sharing in interprofessional practice.' doi: doi: 10.1111/nin.12216.

Ferlie, E. et al. (2005) 'The Nonspread of Innovations: The Mediating Role of Professionals', The Academy of Management Journal, 48(1), pp. 117-134.

Fink, A., Kosecoff, J., Chassin, M., and Brook, R.H. (1984). "Consensus methods: characteristics and guidelines for use". American Journal Public Health, Vol. 74, pp. 979-983.

Fitzgerald, A., and Teal, G., (2003). "Health reform, professional identity and occupational subcultures: the changing interprofessional relations between doctors and nurses". Contemporary Nurse16, pp. 9-19. https://doi.org/10.5172/conu.16.1-2.9

Goodyear, R. K. (2007). "Toward an effective signature pedagogy for psychology: Comments supporting the case for competent supervisors". Professional Psychology: Research and Practice, Vol. 38 No. 3, pp. 273-274.

Gurung, R. A. R., Chick, N. L., Haynie, A. and Ciccone, A.A. (Eds.) (2008). Exploring signature pedagogies: Approaches to teaching disciplinary habits of mind. Sterling, VA: Stylus Publishing

Hogg, M. A. and Abrams, D. (1988) Social identifications: a social psychology of intergroup relations and group processes. London; New York: Routledge.

Hornsey, M.J. and Hogg, M.A. (2000). "Assimilation and diversity: An integrative model of subgroup Relations", Personality \& Social Psychology Review, Vol. 4 No. 2, pp. 143-156.

Institute of Medicine (IOM) (2000). To Err is Human: Building a Safer Health System, National Academy Press, Washington, DC.

Iserson, K. V (2019) "Talking About Professionalism Through the Lens of Professional Identity", AEM Education and Training, 3pp. 105-112. doi: 10.1002/aet2.10307.

Joynes, V.C.T., (2018). Defining and understanding the relationship between professional identity and interprofessional responsibility: implications for educating health and social care students. Advances in Health Sciences Education. Vol. 23, pp. 133-149. https://doi.org/10.1007/s10459-017$\underline{9778-x}$

Kreindler, S. A. Dowd, D.A., Star, N.D.,Gottschalk, T.,. (2012) "Silos and Social Identity: The Social Identity Approach as a Framework for Understanding and Overcoming Divisions in Health Care", Milbank Quarterly. Vol. 90 No. 2, pp. 347-374. doi: 10.1111/j.1468-0009.2012.00666.x.

Kreuger, R. and Casey, M. (2000). Focus groups: A practical guide for applied research, 3rd Edition, Sage Publications Ltd: London.

Larrison, T. and Korr, W. (2013). Does social work have a signature pedagogy? Journal of Social Work Education, Vol. 49, pp. 194-206. https://doi.org/10.1080/10437797.2013.768102

Lotan, D.W., (2019). "Female nurses: Professional identity in question how female nurses perceive their professional identity through their relationships with physicians." Cogent Medicine. Vol. 6, pp. 1-15. https://doi.org/10.1080/2331205x.2019.1666626

Lown, B.A., and Manning, C.F., (2010). The schwartz center rounds: Evaluation of an interdisciplinary approach to enhancing patient-centered communication, teamwork, and provider support. Academic Medicine. Vol. 85, pp. 1073-1081. https://doi.org/10.1097/ACM.0b013e3181dbf741

Lucas, B. (2015). Getting the improvement habit BMH Quality \& Safety, Vol. 25, pp. 400-403. 
McNeil, K.A., Mitchell, R.J., and Parker, V., (2013). Interprofessional practice and professional identity threat. Health. Sociology. Review. Vol. 22, pp. 291-307.

https://doi.org/10.5172/hesr.2013.22.3.291

Meterko, M., Mohr, D.C. and Young, G.J. (2004) Teamwork culture and patient satisfaction in hospitals Med Care, Vol. 42, pp. 492-498.

Mossop, L., Dennick, R., Hammond, R., and Robbé, I.J. (2013) Analysing the hidden curriculum: use of a cultural web. Medical Education, Vol. 47, pp. 134-143.

Nancarrow, S.A., Booth, A., Ariss, S. et al. (2013), Ten principles of good interdisciplinary team work. Human Resources for Health Vol. 11, No. 19 doi:10.1186/1478-4491-11-19.

Nørgård, R.T., Toft-Nielsen, C., and Whitton, N., (2017). Playful learning in higher education: developing a signature pedagogy. International Journal of Play. Vol. 6, pp. 272-282.

https://doi.org/10.1080/21594937.2017.1382997

Norris, P. (2001). "How 'we' are different from 'them': Occupational boundary maintenance in the treatment of musculo-skeletal problems", Sociology of Health and Illness, Vol. 23 No. 1, pp. 24-43.

Olsen, K. and Clark, C. M. (2009). "A signature pedagogy in doctoral education: The leader-scholar community". Educational Researcher, Vol. 38, pp. 216-221.

Richter, J.P., McAlearney, A.S., and Pennell, M.L., (2016). The influence of organizational factors on patient safety: Examining successful handoffs in health care. Health Care Management Review, Vol. 41, pp. 32-41. https://doi.org/10.1097/HMR.0000000000000033

Sambrook, S., (2009). "Critical pedagogy in a health service management development programme Can "critically thinking" managers change the NHS management culture?" Journal of Health Organisation Management, Vol. 23, pp. 656-671. https://doi.org/10.1108/14777260911001662

Shulman, L.S., (2005). "Signature Pedagogies in the Professions". Daedalus. Vol. 134, pp. 52-59. https://doi.org/10.1162/0011526054622015

Siebert, D.C. and Siebert C.F. (2005). "The caregiver role identity scale: A validation study". Research on Social Work Practice, Vol. 15 No. 3, pp. 204-212.

Sinkula, J.M., Baker, W.E. \&and Noordewier, T. (1997). "A framework for market-based organizational learning: linking values, knowledge and behaviour", Journal of the Academy of Marketing and Science, Vol. 25, pp. 305-318.

Stull, C.L., and Blue, C.M., (2016). "Examining the influence of professional identity formation on the attitudes of students towards interprofessional collaboration". Journal of Interprofessional Care, Vol. 30, pp. 90-96. https://doi.org/10.3109/13561820.2015.1066318

Van Maanen, J. and Barley, S.R. (1984). "Occupational communities: Culture and control in organizations". Research in Organizational Behavior. pp. 287-365.

Welsh Government, (2016) Prudent Healthcare Securing Health and Well-being for Future Generations Available at http://www.prudenthealthcare.org.uk/wpcontent/uploads/2016/02/Securing-Health-and-Wellbeing-for-Future-Generations1.pdf Accessed 2.12.19 
Workman, A. and Pickard, J. (2010) "Professional identity in multi-disciplinary teams", Equality, participation and inclusion 2: Diverse Perspectives, Vol. 16 No. 3, pp. 120-129.

\begin{tabular}{|c|c|c|}
\hline Gender & $\mathrm{n}$ & $\%$ \\
\hline Male & 6 & $20 \%$ \\
\hline Female & 24 & $77 \%$ \\
\hline Prefer to self-describe & 1 & $3 \%$ \\
\hline Profession & $n$ & $\%$ \\
\hline Social worker & 9 & $29 \%$ \\
\hline Occupational Therapist & 2 & $6 \%$ \\
\hline Physiotherapist & 1 & $3 \%$ \\
\hline Dietician & 7 & $23 \%$ \\
\hline Clinical Psychologist & 2 & $6 \%$ \\
\hline Doctor & 1 & $3 \%$ \\
\hline Nurse & 3 & $10 \%$ \\
\hline $\begin{array}{l}\text { Other-Dietetic support workers, Dietetic assistant } \\
\text { practitioner, counsellor, Social work assistant, social work } \\
\text { student }\end{array}$ & 6 & $20 \%$ \\
\hline Years since qualified & $\mathrm{n}$ & $\%$ \\
\hline $0-3$ years & 9 & $32 \%$ \\
\hline $4-6$ years & 3 & $10 \%$ \\
\hline $7-10$ years & 7 & $24 \%$ \\
\hline $11-15$ years & 1 & $3 \%$ \\
\hline $20+$ years & 8 & $28 \%$ \\
\hline Years since joined team & $\mathrm{n}$ & $\%$ \\
\hline Up to one year & 8 & $25 \%$ \\
\hline $1-3$ years & 12 & $39 \%$ \\
\hline 4-6 years & 7 & $23 \%$ \\
\hline $7-10$ years & 1 & $3 \%$ \\
\hline $11+$ years & 3 & $10 \%$ \\
\hline Co-located with team & $\mathrm{n}$ & $\%$ \\
\hline Yes & 27 & $87 \%$ \\
\hline Co-located with some colleagues & 3 & $10 \%$ \\
\hline Other - student on placement & 1 & $3 \%$ \\
\hline
\end{tabular}

Table I. Characteristics of focus group participants 


\begin{tabular}{|c|c|}
\hline Stage & Activity \\
\hline 1. & Presentation of previous research and literature on professional identity \\
\hline 2. & Formulation and presentation of the nominal questions $(n=2)$ \\
\hline 3. & Silent generation of ideas in writing $(n=2)$ \\
\hline 4. & $\begin{array}{l}\text { Round-robin feedback from group members to record each idea in a succinct } \\
\text { phrase on a flip chart - continue until all ideas shared }\end{array}$ \\
\hline 4. & Group discussion of each idea in turn for clarification and evaluation \\
\hline 5. & Agree and cluster similar ideas \\
\hline 6. & $\begin{array}{l}\text { Individual voting on priority ideas with the group decision often being } \\
\text { mathematically derived through rank-ordering or rating - each participant had } \\
10 \text { votes to distribute against ideas }\end{array}$ \\
\hline 7. & Feedback of results, further discussion and re-voting \\
\hline 8. & $\begin{array}{l}\text { Feedback of study results (three groups) via written summary and } \\
\text { dissemination event }\end{array}$ \\
\hline
\end{tabular}

Table II: Nominal Group Technique phases. Adapted from Cantrill et al., (1996)

\begin{tabular}{|l|l|l|l|}
\hline Apprenticeship & Code & Description for coding & Example \\
\hline $\begin{array}{l}\text { i) a cognitive apprenticeship } \\
\text { to learn to think like others in } \\
\text { your profession }\end{array}$ & Think & $\begin{array}{l}\text { Items relating to } \\
\text { thinking, conceptual } \\
\text { ideas or thoughts }\end{array}$ & $\begin{array}{l}\text { Lack of understanding of the } \\
\text { team by 1. clients and 2. } \\
\text { other professionals (FG1 } \\
\text { Challenge) }\end{array}$ \\
\hline $\begin{array}{l}\text { ii) a practical apprenticeship } \\
\text { to learn how to perform like } \\
\text { those in your profession }\end{array}$ & Perform & $\begin{array}{l}\text { Practical items that } \\
\text { involve an element of } \\
\text { action }\end{array}$ & $\begin{array}{l}\text { Working within scope of } \\
\text { practice (FG2 Benefit) }\end{array}$ \\
\hline $\begin{array}{l}\text { iii) a moral apprenticeship to } \\
\text { learn how to act with moral } \\
\text { integrity }\end{array}$ & integrity & $\begin{array}{l}\text { Items focused on how } \\
\text { something is done/ } \\
\text { judgement or quality }\end{array}$ & $\begin{array}{l}\text { Promote values, shared } \\
\text { accountability and support } \\
\text { (FG3 Benefit) }\end{array}$ \\
\hline
\end{tabular}

Table III: Apprenticeships coding guide 
Benefits

\section{Focus group 1}

Item

Knowledge and experience of others' roles

Shared responsibility

Sharing problems with the team

Exploring care options

Holistic approach to care

Supporting each other

Problem solving - better

Problem solving - quicker

Easy access to other professions

Upskilling yourself

Benefits

\section{Focus group 2}

\section{Item}

Provide support/supervision and know where to go for them

Patient centred care delivered

Deliver education from different

perspectives

\begin{tabular}{lll}
\hline Working within scope of practice & 9 & Perf \\
\hline Feeling part of team and belonging & 9 & Think \\
\hline $\begin{array}{l}\text { Wider skill set due to blurring boundaries } \\
\text {..more job security }\end{array}$ & 9 & Act \\
\hline Better patient care & 8 & Think \\
\hline Ability to provide bespoke view or opinion & 8 & Act \\
\hline Clarity of role and boundaries & 7 & Think \\
\hline Different perspectives on care & 7 & Think \\
\hline
\end{tabular}

\section{Benefits}

\section{Focus group 3}

Item

Promote values, shared accountability and support

Team around the person/patient/user

Better understanding of one another's role 1

Clear team structure, accountability and delegation

Communication across the team votes code

11 Perf

11 Perf

10 Perf

(20)

votes code

13 Act

12 Act

Think

11 Perf

$9 \quad$ Perf

\section{Challenges}

Item

votes

code

Management by other professions

Working outside own professional role(s)

9

Perf

Working outside own "comfort zone"

Difficulty/ inability to say 'no' to another team member

Lack of understanding of the team by i) clients and ii) other professionals

Not understanding other roles especially when new to the team

Think

9

Think

8

Act

8

Think

Potential for duplication of care 7

Potential for duplication of care

Getting right service to client at right time

Different work timescales/ethics

Confusing for clients

Think

\section{Challenges}

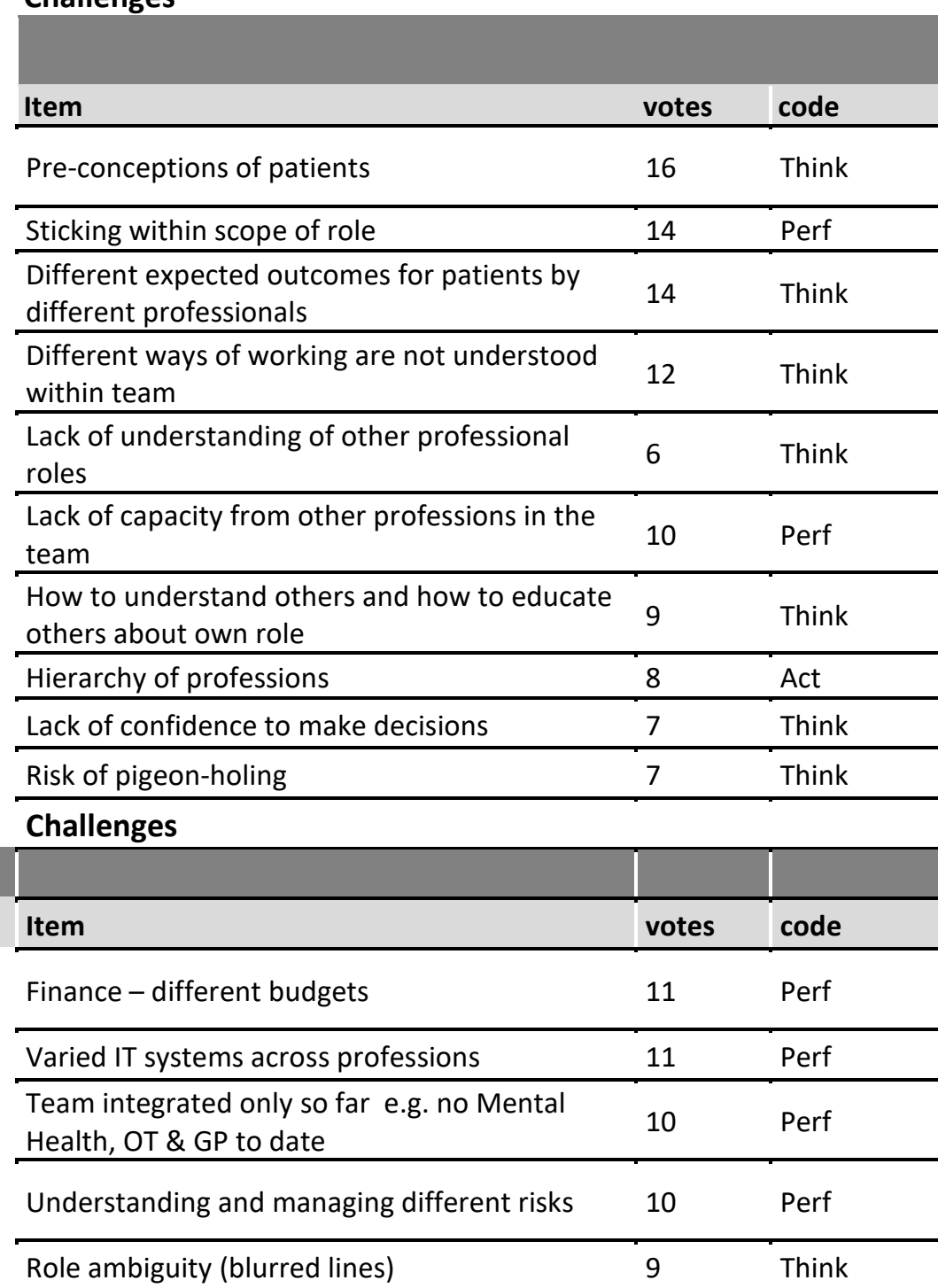




\begin{tabular}{lcc}
\hline Holistic approach to care & 7 & Act \\
\hline Professional pride in leading the way & 6 & Act \\
\hline $\begin{array}{l}\text { Understand own skills/knowledge and } \\
\text { shared expertise }\end{array}$ & 6 & Think \\
\hline Develop and enhance professional learning & 6 & Think \\
\hline Good for team morale and cohesiveness & 5 & Act
\end{tabular}

\begin{tabular}{lll}
\hline $\begin{array}{l}\text { Different culture, approach and values for each } \\
\text { profession }\end{array}$ & 7 & Act \\
\hline Shared team vision & 7 & Think \\
\hline $\begin{array}{l}\text { Different policies in different organisations } \\
\text { Different employers }\end{array}$ & 5 & Perf \\
\hline $\begin{array}{l}\text { Public perceptions of the professions and the } \\
\text { team }\end{array}$ & 4 & Perf \\
\hline
\end{tabular}

Table IV. Data from Nominal Group Technique Activity 


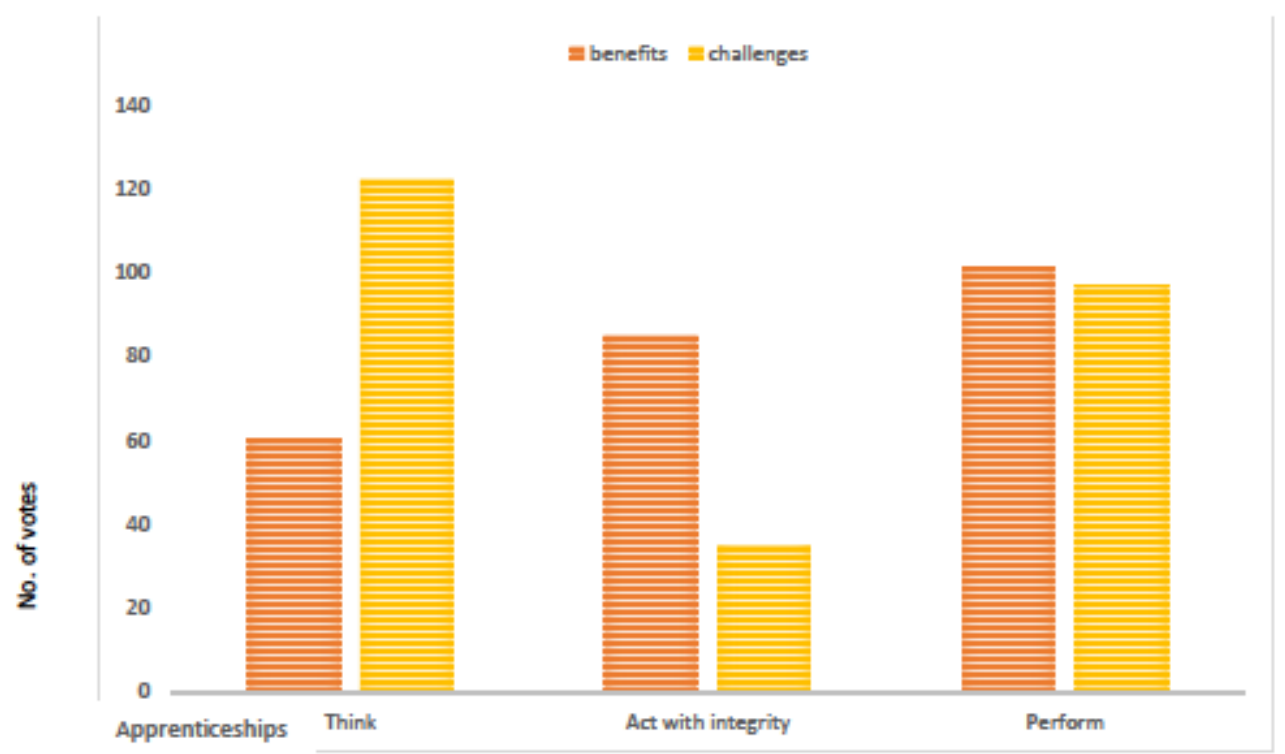

Figure 1: Cumulative ranking of findings by signature pedagogy apprenticeship.

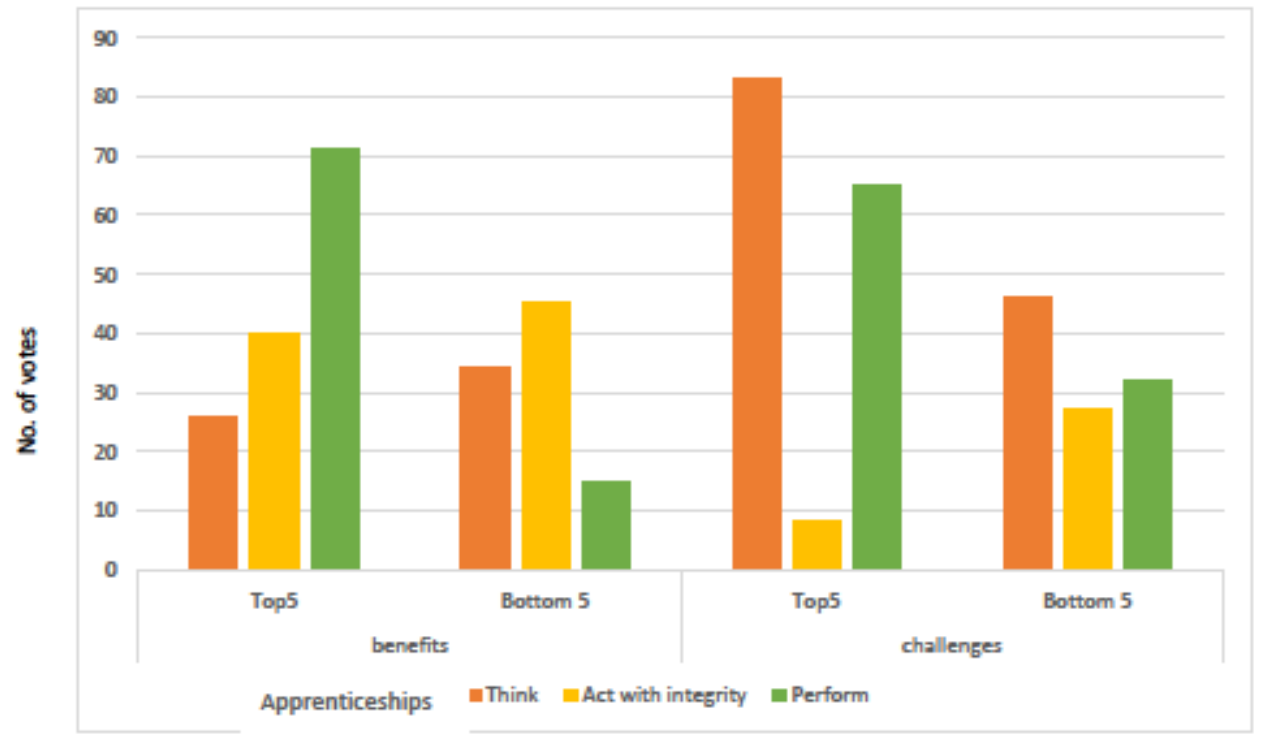

Figure 1: Coding by signature pedagogy: Highest and lowest ranked benefits and challenges of professional Identity in an interprofessional Teams 